\title{
Pulmonary Surfactant Release in Fetal Rabbits as Affected by Enprofylline
}

\author{
LAILA EKELUND ${ }^{1}$ AND GORAN ENHORNING \\ Department of Obstetrics and Gynaecology, University of Toronto, Toronto, Ontario, Canada
}

\begin{abstract}
At a gestational age of 27.9 days, pregnant rabbits were infused with enprofylline, a new xanthine with potent antiasthmatic effects. Following a priming dose of $5 \mathrm{mg} / \mathrm{kg}, 20 \mathrm{mg} / \mathrm{kg}$ were infused over a 2 -h period. Controls received Ringer's solution. On completion of the infusion, the fetuses were delivered and the effect on their surfactant system was evaluated. Surface tension in airway fluid, measured with the pulsating bubble surfactometer, at minimal bubble size in the third cycle, was $21.8 \pm 2.2$ (mean $\pm \mathrm{SE})$ versus $28.7 \pm 1.7 \mathrm{mN} \mathrm{m}^{-1}(p<0.01)$. Pressurevolume loops of the lungs of the fetuses showed that at a deflation pressure $10 \mathrm{~cm} \mathrm{H}_{2} \mathrm{O}$ the volume was $64 \pm 3$ versus $49 \pm 3 \%$ ( $p<0.0005)$. The lung lavage fluid had a phospholipid phosphorus content of $41.9 \pm 3.8$ versus 18.5 $\pm 1.3 \mu \mathrm{g} / \mathrm{g}$ dry lung $(p<0.0005)$. The values indicate that enprofylline caused a release of surfactant into the fetal airways. (Pediatr Res 19: 1000-1003, 1985)
\end{abstract}

Respiratory distress syndrome in the newborn is associated with a deficiency of pulmonary surfactant, the main component of which is dipalmitoylphosphatidylcholine (1). A number of pharmacological agents have been found to influence the synthesis of pulmonary surfactant. The effect of glucocorticoids has been studied most extensively, and accelerated lung maturation has been demonstrated in experimental $(2,3)$ as well as clinical studies $(4,5)$. Xanthines are widely used in lung diseases such as asthma and apnea in premature infants, but the mechanism of action of these drugs is still relatively unknown. Increased release of pulmonary surfactant into the alveolar space might be one effect of xanthines. Several animal studies indicate increased synthesis and/or secretion of fetal surfactant after administration of aminophylline (theophylline ethylenediamine) to the mother or directly to the fetus $(3,6,7)$, but other studies have not confirmed this effect (8). Enprofylline (3-propylxanthine), a new xanthine derivative, exhibits potent antiasthmatic characteristics (9). However, the effects of this substance and those of theophylline differ in several respects; most importantly, theophylline is a potent adenosine antagonist, while enprofylline is not (10). Our investigation is an assessment of fetal surfactant release following enprofylline infusion to the doe.

\section{MATERIALS AND METHODS}

Eight pregnant New Zealand rabbits were used. Time of mating was known within $1 \mathrm{~h}$. At a gestational age of 27.9 days (term 31 days), four does were injected intravenously with enprofylline,

Received December 31, 1984; accepted May 16, 1985.

Reprint requests Goran Enhorning, M.D., Toronto Western Hospital, 399 Bathurst Street, Toronto, Ontario, Canada M5T 2S8.

Supported by Medical Research Council of Canada Grant MT-4497.

1 On leave of absence from the Department of Obstetrics and Gynecology, University of Lund, Allmänna Sjukhuset, Malmö, Sweden.
$5 \mathrm{mg} / \mathrm{kg}$, during a 5 -min period, and, in an identical manner, four controls received the same volume of Ringer's solution. Following this loading dose, the rabbits were continuously infused over the next $2 \mathrm{~h}$ with enprofylline, $20 \mathrm{mg} / \mathrm{kg}$, and the controls with the same volume of Ringer's solution. On completion of the infusion, the maternal rabbits were killed with a lethal intravenous dose of thiopental sodium and the abdomen was opened. To prevent the fetuses from making inspiratory efforts, they were injected intracranially with $0.5 \mathrm{ml}$ thiopental sodium while still in utero. The fetuses then were delivered through uterine incisions. The trachea of each fetus was exposed, and a polyethylene tube (PE 50) was inserted just below the larynx. From each fetus, about $25 \mu \mathrm{l}$ of lung fluid was collected for evaluation of surface activity with the pulsating bubble surfactometer (11). This instrument is particularly appropriate for assessing the effect that surface properties of fetal pulmonary fluid will have on the initial aeration with the first breath and on subsequent breathing. The surfactometer's sample chamber, filled with the airway fluid, communicates with ambient air through a vertical capillary. As fluid is withdrawn from the chamber, air is forced to move down the capillary, the cylindrical "airway," and a bubble, with a radius of $0.55 \mathrm{~mm}$, is developed. While the first breath is thus simulated, the negative pressure in the sample liquid surrounding the bubble is recorded. Subsequent "breathing" is by the action of a pulsator which causes the bubble radius, $R$, to oscillate from maximal to minimal size, from 0.55 to $0.4 \mathrm{~mm}$. The pulsator speed is usually set at 20 cycles $/ \mathrm{min}$. Knowing the values of the pressure difference across the bubble's surface, $\Delta P$, and of $R$, surface tension, $\gamma$, can be calculated with the law of Laplace, $\triangle \mathrm{P}=2 \gamma / \mathrm{R}$. In this study, the adsorption rate, the speed with which a monolayer is formed at the bubble surface, was of particular interest. Pressure was therefore recorded while the bubble was first created and then maintained at maximal size for $10 \mathrm{~s}$. The pulsator then was started. From the pressure tracing, $\gamma$, was obtained 2 and $10 \mathrm{~s}$ after bubble creation while the radius was maintained at maximal size, and also in the third cycle of pulsation when the radius was at maximal and at minimal size. The value of $\triangle \mathrm{P}$ decreases continuously during the $10 \mathrm{~s}$ the bubble is maintained at maximal size, and the rate of change reflects interface adsorption of surfactant molecules. Pulmonary fluid from a fetus at term, 31 days, shows very fast adsorption, and after $10 \mathrm{~s}, \Delta \mathrm{P}$ indicates that surface tension is approximately $27 \mathrm{mN} \mathrm{m}^{-1}$, and this low value is already reached after $2 \mathrm{~s}$. Lung compliance and stability were then assessed, as previously described (12), by photographic recording of the pressure-volume loops of all fetuses in a litter. Two consecutive loops were obtained by recording volume as pressure was changed from 0 to $10,20,30,35,30,20,10$, and back to $0 \mathrm{~cm} \mathrm{H}_{2} \mathrm{O}$, each level being maintained for $15 \mathrm{~s}$.

Following pressure-volume loop recording, the lungs were degassed by repeatedly exposing the whole fetuses to vacuum. The lungs were then lavaged with saline in a volume which in $\mathrm{ml}$ was one-tenth the body weight in $\mathrm{g}$. This volume was divided into three equal portions for the same number of washings, each 
consisting of injecting and withdrawing the saline once only. The amount of liquid retrieved was $90-100 \%$ of the saline instilled. The lipids were extracted according to the method of Folch et al. (13), and the total phospholipid phosphorus was quantitated, as described by Rouser et al. (14). Following lavage, the lungs were removed and dried for $24 \mathrm{~h}$ in an oven at $100^{\circ} \mathrm{C}$. The volume of air in $\mathrm{ml}$ entering the lungs and the phospholipid content in $\mu \mathrm{g}$ of phospholipid phosphorus were expressed per $\mathrm{g}$ dry lung. To make certain that the enprofylline had indeed passed the placenta, concentration of the drug was determined in the myocardium of some of the fetuses and in maternal serum.

Student's $t$ test was used for significance evaluation of the difference between mean values found in this study. $p$ values $>0.05$ were considered not significant.

\section{RESULTS}

There were 31 fetuses from the four does receiving enprofylline and 32 from the four controls. The fetuses exposed to the drug weighed slightly more, $36.2 \pm 0.8 \mathrm{~g}$ (mean $\pm \mathrm{SE}$ ) versus $33.5 \pm$ $0.9 \mathrm{~g}(p<0.025)$. There was no difference in fetal dry lung weight, $96.3 \pm 2.8$ and $96.4 \pm 2.7 \mathrm{mg}$, respectively. Enprofylline concentration, determined in the myocardium of 30 fetuses, was $16.9 \pm 0.5 \mu \mathrm{g} / \mathrm{g}$ tissue (mean $\pm \mathrm{SE}$ ), and in maternal serum was $34.1 \pm 2.2 \mu \mathrm{g} / \mathrm{ml}(n=4)$.

Infusion of enprofylline to the pregnant rabbit resulted in several significant changes, all indicating an increased release of pulmonary surfactant into the fetal airways. Surface tension decreased in fetal pulmonary fluid, total phospholipid phosphorus increased in the lavage (Table 1), and lung expansion was greater throughout the first (Fig. 1) as well as the second loop (Fig. 2). When the volume of air retained at deflation pressure $10 \mathrm{~cm} \mathrm{H}_{2} \mathrm{O}$ was expressed as a percentage of the volume at maximal expansion, it was $64 \pm 3$ (mean \pm SE) for the enprofylline-exposed fetuses and $49 \pm 3$ for the controls in the first loop, and in the second loop the corresponding figures were 71 \pm 3 and $52 \pm 5$. These figures indicate that the enprofyllineexposed fetuses had lungs with significantly greater stability ( $p$ $<0.0005)$

\section{DISCUSSION}

On the average, the fetuses receiving enprofylline weighed more than did the controls. Since the time of mating was carefully controlled, it is unlikely that this was due to a difference in gestational age, which could be no more than $1 \mathrm{~h}$. Theophylline is a potent diuretic, perhaps because it inhibits intrarenal actions of endogenous adenosine. Enprofylline, exerting no such inhibition, is definitely not a diuretic and in high dose, $20 \mathrm{mg} / \mathrm{kg}$, reduces urinary excretion of sodium in the rat (15). We believe that the higher weight of the fetuses exposed to enprofylline could be due to edema developing; there was no difference in the dry lung weight.

In our statistical analysis, the number of fetuses was our $n$ value. Abbey and Howard (16) are of the opinion that this is inappropriate because the offspring of one female may differ from that of another and because the mother's reaction to a treatment may vary and could influence a whole litter. Instead, they suggest that the SD should be calculated from the means of the litters. Obviously, this will drastically reduce the degrees of freedom. It is undoubtedly true that maternal factors, such as gestational age, will affect an entire litter and hence should be

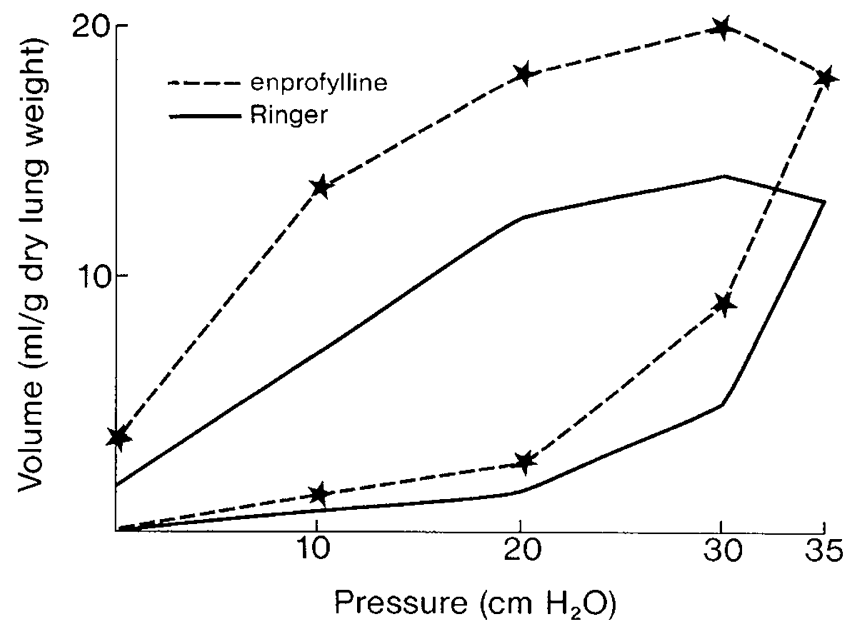

Fig. 1. The mean volume of air entering into and retained in the lungs as pressure is initially raised stepwise to $35 \mathrm{~cm}$ water and then lowered again to zero. Asterisk indicates that the volume in the enprofylline group is significantly greater $(p<0.005)$.

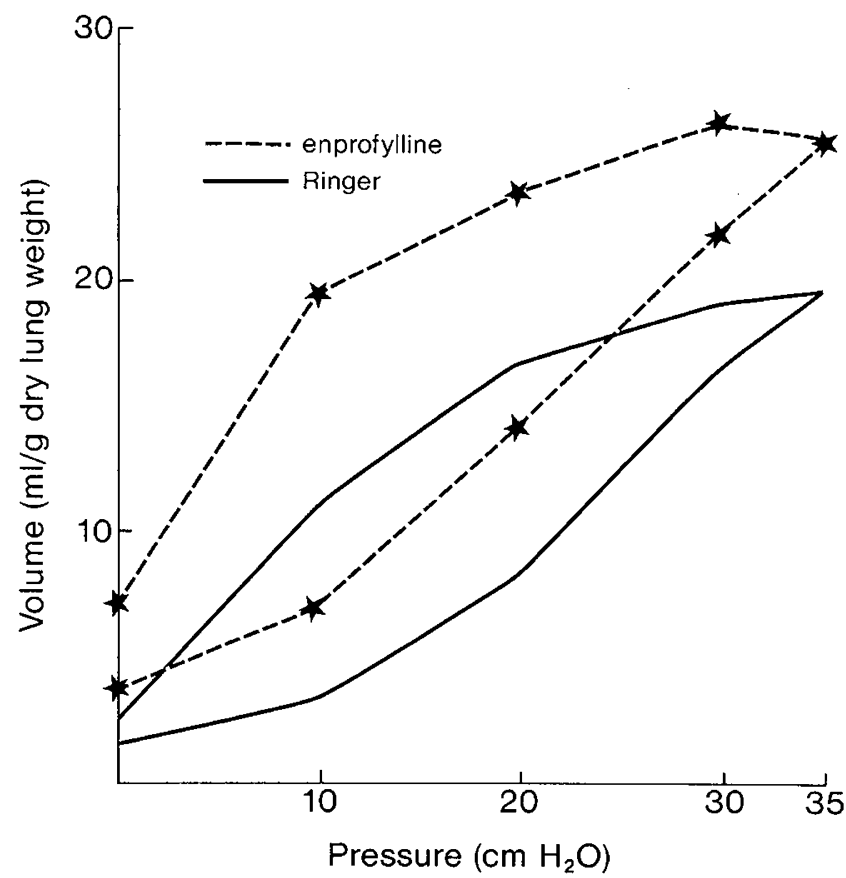

Fig. 2. Difference in compliance and stability during second pressurevolume loop. Asterisks as in Figure 1.

Table 1. Surface tension, $\gamma$, of fetal lung fluid $\left(\mathrm{mN} \mathrm{m}^{-1}\right)$, and phospholipid phosphorus content, PL-P, of fetal lung lavage fluid ( $\mu \mathrm{g} / \mathrm{g}$ dry lung $w t)$

\begin{tabular}{|c|c|c|c|c|c|}
\hline & \multicolumn{2}{|c|}{$\begin{array}{l}\text { Bubble not pulsating, main- } \\
\text { tained at maximal size }\end{array}$} & \multicolumn{2}{|c|}{ Bubble pulsating in 3rd cycle at } & \multirow[b]{2}{*}{ PL-P } \\
\hline & $2 \mathrm{~s}$ & $10 \mathrm{~s}$ & Maximal size & Minimal size & \\
\hline Enprofylline $(n=31) \dagger$ & $44.0 \pm 1.8^{*}$ & $40.2 \pm 1.6$ & $44.6 \pm 1.8$ & $21.8 \pm 2.2$ & $41.9 \pm 3.8$ \\
\hline Ringer $(n=32)$ & $48.6 \pm 1.2$ & $44.4 \pm 1.1$ & $49.2 \pm 1.4$ & $28.7 \pm 1.7$ & $18.5 \pm 1.3$ \\
\hline$p$ & $<0.025$ & $<0.025$ & $<0.05$ & $<0.01$ & $<0.0005$ \\
\hline
\end{tabular}

$*$ Mean $\pm \mathrm{SE}$.

$\uparrow$ Number of fetuses. 
kept equal for each doe. There are indisputable differences between individual fetuses within a litter, for instance, in body size. We therefore considered it appropriate to regard each fetus as an individual, receiving the drug infused to the mother in a dose equal to that affecting its littermates. We did, however, also calculate the $p$ value in the conservative manner suggested by Abbey and Howard (16), and found that the differences in phospholipid phosphorus content and in air retention at deflation pressure $10 \mathrm{~cm} \mathrm{H}_{2} \mathrm{O}$ of the first loop were still significant $(p<$ 0.01 and $<0.05$, respectively).

In the past, pulmonary surfactant has often been evaluated on the basis of one parameter only, its ability after several minutes to lower surface tension to close to zero on surface area compression. This reflects an important stabilizing effect, but surfactant clearly has other equally important qualities, such as quick adsorption and respreading (17), which are difficult to appreciate with the modified Wilhelmy balance, as generally used. The initial aeration requires that surface tension be lowered at the air-liquid interfaces as these move down the cylindrical airways toward the alveoli. This requires the extremely fast adsorption that characterizes pulmonary fluid from a fetus at term. As soon as $2 \mathrm{~s}$ after bubble expansion in each fluid, a very low surface tension will be observed with the bubble surfactometer. Fast adsorption of surfactant into an expanding interface between pulmonary fluid and air will also result in increased compliance of the lung, so that with moderate time of raised pressure in the airways (we used $15 \mathrm{~s}$ for each pressure level) the lungs will become well aerated and total lung capacity is increased. Our results implied that adsorption was improved in the airway fluid of neonates exposed to enprofylline in utero; surface tension was already lower after $2 \mathrm{~s}$ and more air moved into the lung when tracheal pressure was raised. The greater volume of air retained in the lung during deflation, a sign of improved stability, was another indication that surfactant had been released into the airways of pups exposed to enprofylline. Finally, our finding of higher levels of total phospholipids in lavage fluid also offered strong evidence of surfactant release following enprofylline treatment.

Previous reports on the xanthine effects on synthesis and release of pulmonary surfactant have been conflicting. Following treatment with theophylline, increased synthesis of fetal pulmonary surfactant has been observed, in vitro as well as in vivo. Thus, Gross and coworkers $(18,19)$ found that the drug caused an increased incorporation of choline into phosphatidylcholine in fetal rat lung studied in organ culture. Following theophylline injections given to pregnant rabbits for 7-10 days, Karotkin et al. (20) noted increased amounts of phospholipids in fetal lung tissue and lavage fluid, and they found compliance to be higher. Their results are similar to those reported by Barrett et al. (21). A recent article (22) reports on the effect of treating pregnant rabbits for 2 days with aminophylline, beginning at 25.5 days' gestation. This produced a significant total phospholipid increase in fetal lung tissue, but there was no such increase in lung lavage.

In short-term experiments, Corbet et al. (7) studied the release of fetal pulmonary surfactant. They injected fetal rabbits in utero with theophylline at a gestational age of 27.5 days. When sacrificed $2.5 \mathrm{~h}$ later, the lungs of theophylline-treated fetuses retained more air at deflation pressure $10 \mathrm{~cm} \mathrm{H}_{2} \mathrm{O}$, and total phospholipids, recovered from lung lavage fluid were higher, indicating increased release of pulmonary surfactant. However, using similar methods and the same dose of theophylline, we were unable to confirm these results (8) and, in accordance with our observations in the rabbit, Gross et al. (personal communication) found that there was no increased release of fetal pulmonary surfactant after infusion of pregnant rats with different dosages of theophylline.

Our own results may seem conflicting. With theophylline, we were unable to find an increased surfactant release (8), whereas we have now found that, following exposure to enprofylline, surfactant is released into the fetal airway. This requires an analysis and a comparison of the mode of action of the two xanthines. It has been suggested that cAMP may be a mediator of synthesis and/or secretion of fetal pulmonary surfactant (21). In high concentrations, xanthines increase cAMP by inhibiting phosphodiesterase, the enzyme inactivating cAMP (23), and thus might stimulate the appearance of pulmonary surfactant into fetal airways. Xanthines are widely used in asthma therapy and their mechanisms of action on this disease have been studied extensively. A recent review by Persson (24) presents reasons why it is doubtful that a xanthine is of benefit to the asthmatic by virtue of being a phosphodiesterase inhibitor. At therapeutic plasma concentrations, the bronchorelaxant effect of theophylline is unlikely to be mediated by cAMP (25). Enprofylline exhibits potent antiasthmatic characteristics, while lacking several of theophylline's side effects $(9,24)$. This might be due to an important difference in the action of the two drugs. While theophylline is a potent adenosine antagonist $(26,27)$, enprofylline is almost totally unable to compete for receptor sites (24). Since adenosine regulates adenylate cyclase and increases intracellular cAMP in several cell systems $(24,25)$, it probably promotes surfactant release, and it is conceivable that enprofylline has the ability to exert surfactant release because it lacks the adenosine antagonistic effects of other xanthines. This is an area obviously requiring further investigation. We are presently making direct comparisons between theophylline and enprofylline and we are evaluating the hypothesis that adenosine per se promotes surfactant release.

\section{REFERENCES}

1. Farrell PM, Avery ME 1975 Hyaline membrane disease. Am Rev Respir Dis 111:657-688

2. DeLemos RA, Shermeta DW, Knelson JH, Kotas R, Avery ME 1970 Acceleration of appearance of pulmonary surfactant in the fetal lamb by administration of corticosteroids. Am Rev Respir Dis 102:459-461

3. Ekelund $\mathrm{L}$, Arvidson G Astedt B 1975 Cortisol induced accumulation of phospholipids in organ culture of human fetal lung. Lab Invest 35:419-423

4. Ekelund L, Arvidson G, Ohrlander S, Astedt B 1976 Changes in amniotic fluid phospholipids on treatment with glucocorticoids to prevent respiratory distress syndrome. Acta Obstet Gynecol Scand 55:413-417

5. Liggins GC, Howie RN 1972 A controlled trial of antepartum glucocorticoid treatment for prevention of the respiratory distress syndrome in premature infants. Pediatrics 50:515-525

6. Barrett CT, Sevanian A, Phelps PL, Gilden C, Kaplan SA 1978 Effects of cortisol and aminophylline upon survival, pulmonary mechanics, and secreted phosphatidyl choline of prematurely delivered rabbits. Pediatr Res $12: 38-42$

7. Corbet AJ, Flax P, Alston C, Rudolph AJ 1978 Effect of aminophylline and dexamethasone on secretion of pulmonary surfactant in fetal rabbits. Pediatr Res 1:797-799

8. Ekelund L, Burgoyne R, Brymer D, Enhorning G 1981 Pulmonary surfactant release in fetal rabbits as affected by terbutaline and aminophyllin. Scand J Clin Lab Invest 41:237-245

9. Persson CGA, Kjellin G 1981 Enprofylline, a principally new antiasthmatic xanthine. Acta Pharmacol Toxicol 49:313-316

10. Persson CGA 1983 The profile of action of enprofylline, or why adenosine antagonism seems less desirable with xanthine antiasthmatics. In: Morely J, Rainsford KD (eds) Pharmacology of Asthma, Vol 115. Birkhauser, Basel, pp 115-129

11. Enhorning G 1977 Pulsating bubble technique for evaluating pulmonary surfactant. J Appl Physiol 43:198-203

12. Enhorning G, Robertson B 1972 Lung expansion in the premature rabbit fetus after tracheal deposition of surfactant. Pediatrics 50:58-66

13. Folch J, Lees M, Sloane-Stanley GH 1957 A simple method for isolation and purification of total lipids from animal tissues. J Appl Physiol 226:497-509

14. Rouser G, Sakotes A, Fleischer S 1966 Quantitative analysis of phospholipids by thin-layer chromatography and phosphorus analysis of spots. Lipids 1:85-

15. Persson CG, Erjefält L, Karlsson JA 1981 Adenosine antagonism, a less desirable characteristic of xanthine drugs? Acta Pharmacol Toxicol 49:317320

16. Abbey H, Howard E 1973 Statistical procedure in developmental studies on species with multiple offspring. Dev Psychobiol 6:329-335

17. Notter R, Finkelstein JN 1984 Pulmonary surfactant: an interdisciplinary approach. J Appl Physiol 57:1613-1624

18. Gross I, Rooney SA 1977 Aminophylline stimulates the incorporation of choline into phospholipid in explants of fetal rat lung in organ culture. Biochim Biophys Acta 488:263-269

19. Gross I, Wilson CM 1982 Fetal lung in organ culture. IV. Supra-additive hormone interactions. J Appl Physiol 52:1420-1425 
20. Karotkin EH, Masamitsu K, Cashore WJ, Redding RA, Douglas WJ, Stern L, Oh W 1976 Acceleration of fetal lung maturation by aminophylline in pregnant rabbits. Pediatr Res 10:722-724

21. Barrett CT, Sevanian A, Lavin N, Kaplan SA 1976 Role of adenosine 3'5'monophosphate in maturation of fetal lungs. Pediatr Res 10:621-625

22. Landers S, Corbet A, Cregan J, Frink J, Rudolph AJ 1984 Effect of aminophylline and caffeine on total and surfactant phospholipid in fetal rabbit lung. Am Rev Respir Dis 130:204-208

23. Butcher RW, Sutherland EW 1962 Adenosine 3' 5 '-monophosphate in biological materials. J Biol Chem 237:1244-1250
24. Persson CGA 1984 The pharmacology of antiasthmatic xanthines and the role of adenosine. In: Morley J (ed) Asthma Reviews, Vol I. Academic Press, New York (in press)

25. Bergstrand H 1980 Phosphodiesterase inhibition and theophylline. Eur J Respir Dis 61 (suppl 109):37-44

26. Fain JN, Malbon CC 1979 Regulation of adenylate cyclase by adenosine. Mol Cell Biochem 25:143-169

27. Londos C, Wolff J, Cooper DMF 1981 Adenosine receptors and the regulation of adenylate cyclase. In: Burnstock $\mathrm{G}$ (ed) Purinergic Receptors. Chapman and Hall, London, pp 287-323

\section{ANNOUNCEMENTS}

\section{International Symposium}

The symposium "Recent Aspects on Diagnosis and Treatment of Lipoprotein Disorders: Impact on Prevention of Atherosclerotic Diseases" will take place in Vienna, Palais Auersperg, August 21-23, 1986. For information contact: Dr. K. Widhelm, Department of Pediatrics, University of Vienna, Währinger Gürtel 18, A-1090 Vienna, Austria.

\section{6th International Postgraduate Course}

"Anesthesia and Intensive Care for Infants and Children", 6th Myron B. Laver International Postgraduate Course, will be held March 14-15, 1986. For details contact: Secretariat, Department of Anesthesia, University of Basel/Kantonsspital, CH-4031 Basel, Switzerland.

\section{Awards in Clinical Research}

Nomination material is now available for The 1986 Lita Annenberg Hazen Awards for Excellence in Clinical Research. The purpose of the awards is to encourage increased participation in clinical research be physicians. Prizes amounting to $\$ 100,000$ are awarded: $\$ 50,000$ (tax free) to an outstanding physician investigator and $\$ 50,000$ for the support of a research fellow(s).

For further information contact: James F. Glenn, M.D., President, The Mount Sinai Medical Center, Chairman, the Lita Annenberg Hazen Awards Program, One Gustave L. Levy Place, New York, NY 10029; or call (212) $650-8832$. 